\title{
The Problem of Alienation in Objective Spatiality
}

\author{
Gregory Victor Loewen \\ Department of Sociology, STM College, University of Saskatchewan \\ 1437 College Drive, Saskatoon, SK Canada S7N 0W6. E-mail: gloewen@stmcollege.ca
}

Received: January 19, 2015 Accepted: June 16, 2015 Published: June 19, 2015

doi:10.5296/jsss.v2i2.7861 URL: http://dx.doi.org/10.5296/jsss.v2i2.7861

\begin{abstract}
Globalization has created an immense sense of objectivity in the world. We find the differences between cultures foreshortened, others more recognizable and less alien, other places more like our own, and transactions and contracts more and more adhering to the specifically acultural denomination of capital. But external spatiality and the actions within it are not the only places of generalization and alienation. The agora of public space has been internalized to the extent that we as subjects feel ourselves to be more confident of our objectivity in worldly relations. The paper questions the assumptions and analyses the structures that lay behind the link between a global externality and our sense that the world can be a wider home for our personhood and individuated beings.
\end{abstract}

Keywords: Alienation, Agora, Heidegger, Spatiality, Watsuji 


\section{Introduction}

We are immediately lost in the generality of objective space. We cannot find ourselves within it. It is a space for all of us, and thus also for none of us. Yet since we require the spatial self to be human at all, we must force ourselves into such a space and attempt to communicate with the 'everyone else' who may be doing the same thing: "There are signs that the link with spatial orientation lies very deep in the human psyche." (Taylor, 1989:28). Taylor references the observation that in some forms of mental illness like 'narcissistic personality disorders' the subject loses his sense of that orientation, quite literally not recalling where he is. Theater aside, it does make sense that the collapse of the cosmos into and unto oneself would also include the implosion of any general geography. Autotopology is itself an effort in orienting oneself in 'effective topological consciousness' and thus must be seen as a bulwark against narcissism: "The disorientation and uncertainty about where one stands as a person seems to spill over into a loss of grip one one's stance in physical space." (ibid). One could be, in other words, quite literally anywhere. Yet one is never just anywhere. Today, where there are people, there is at least some semblance of regional place. Not every single GPS point on the globe can be said to have a name of its own. But if there is someone nearby to ask, one will likely get some kind of response. Sometimes it will even be the somewhat archaic response that 'the natives call it this or that'. At worst, one will be able to cite latitude and longitude. The globe girdling compass of geographic comportment is an assurance against the ultimate spatial anomie of imagining oneself to have become the cosmic whole. This is why, as in most forms of mental illness, one is always suspicious that the duplicity of altered consciousness includes the play-acting of the con. No one, in the midst of his fellow humans, loses complete sight of the intersubjective component of human interaction. Just so, we cannot not know we are oriented in space in some way. We continue to exist as spatial beings, even creatures, even if we have permanently lost the ability to make ourselves into a spatial self. Indeed, this kind of disability may have to be associated with the metaphysics of temporality that displaces place into space, which makes the more specific where into 'just anywhere': "The space whose properties are grasped in ideas is the total space, which can be represented, however, only in a dimension of infinite time." (Lingis, 1989:12). The more abstract the ideas are, the more continuous and infinite time becomes, ironically perhaps, to 'hold' these ideas in a space of 'their own'. Abstraction, the essence of anywhere, also fraudulently fronts ideas as if they could be 'timeless' or 'essential'. Artefacts of a social reality that was itself unchanging for great lengths of historical time - the agrarian periods in fact pale when compared to their predecessors, especially with the primordial epochs, geological in scope, when our human forebears carried on for millions of years without doing anything differently - the 'Ideas' are called forth today only either in the space of academic refugiae or by politicians stumping in the hopes of constructing some kind of mock mechanical solidarity amongst a realistically diverse citizenry. No, the objectivity of anywhere is a theater through and through, and to lose our sense of self in it may well be a mental illness in so far as it can be evidenced that one has done so unwillingly.

\subsection{Immediate Implications for a Phenomenology of Space}

Meaningful space is thus placed at a disadvantage in the Agora of anywhere. The 'openness 
of possibilities' in Heidegger must itself be reflected upon. With the open space of the agora that can be entered and exited in the same way by anyone, it does appear that anything is possible, but this is not saying the same thing. 'Openness' is also a function of a symbolic system that has its deportment within the spatial self as our interiority. The anonymity of the 'nothing meant' in agora absorbs our enactmental potential and reflects it back to us with an unfailing mirror. We see, in agora, only what the world sees of us. This may or may not be what we wish to see. The mirror of open space is unreflective even though it reflects. Because anywhere is one aspect of objective and objecting spatiality, it should "...not be confused with the abstract space of the objective sciences, particularly the space of mathematics and physics, which are derivates of the former. Watsuji follows Heidegger's insights when he claims that ningen is not oriented towards abstract points in an objective space but towards a space of a symbolic life-world, or as he puts it, a space that is structured by 'expressions' which are the correlates of ningen's practical understanding." (Liederbach, 2012:127). Meaningfulness is what makes space our own, to live in and live with as human beings. This never comes out of the space 'itself'. Space is not an essence, not an idea. The meaning of the 'Ideas' is as well constructed by real living beings who seek to understand themselves in space and time. Abstraction is necessary to the structure of any kind of consciousness, but we do not theorize our way through life: "The spatiality exhibited by these phenomena of human transportation and communication is clearly subjective extendedness. It interconnects both subjectively and practically but lacks the same extendedness as an objective thing. This subjective extendedness arises because human beings, despite dividing themselves into a great number of subjects, nevertheless, strive to constitute a connection among themselves." (Watsuji, in Liederbach, op. cit. 128). It is fair to say that the mass market of sameness that one encounters in agora generally acts against the subject. It de-individualizes persons and makes them more into mobile and sentient things in the object realm. But it does so precisely in order to make the world safer for objects 'themselves', to foster connections not within subjectivity, but within the abstraction of thing-hood. Ritzer's conception of 'nothing' is, with apt irony, able to inform a discussion about the being of something other than being in the world. The surfeit of spaces within which 'nothing' occurs, that is, nothing new and different than what we have undertaken and undergone a thousand times before, the 'fast food nationality' of our collective citizenship, is a sure sign of the presence of agora. This spatiality portrays itself as part of who we are. If this is indeed the case, we are all suffering from some sort of mild but persuasive 'narcissistic disorder' of the person. Having an object 'the way you want to' is one such slogan of this disorientation. The world in its authenticity is manifestly not the way we want it to be, either in its social reality or in its nature. Our species lives in its ecology through evolutionary adaptation, more cultural than biological these days of course, but nevertheless, it is we that must change to follow the world. In agora, the world follows us around like some polyester pest, spreading its simple and shallow gospel on every street-corner. To take its pamphlets and tracts is to retract the act of being human ourselves, to give over our humanity in the face of the ease of doing 'nothing, quite literally, in the spaces where all is done for us, including the art and task of reflection and even of phantasm. Watsuji argues against such spaces and their interpretation as being true to the social world of extended subjects. Rather, such a space is the attempt to extend the object into oneself. It does 
present to us a sense that living can be made more practical through the ease and simplicity of its designing forces, and through thus it allows us to slide into a spurious correlation between the pragmatism of symbolic intersubjectivity and the 'we do it all for you' mentality of the agora. Spacious but specious, the anywhere of anything at anytime for anyone leaves us stranded on the uniform sands of the Ideas and of timelessness, the ironic contemporary response to the challenge of interpreting our own Rhodian traces.

Watsuji continues by arguing that the authentic space of being in the world, the space that is cloistered from itself an suppressed in the agora, is actuated by being sable to experience what lies between humans as yet part of ourselves. This spatiality “...is not a uniform extendedness, but a dialectical one, in which relations such as 'near and far, wide and narrow' are mutually transformed into one another. In a word, it is the betweenness itself of subjective human beings." (Watsuji, in McCarthy, 2014:4). Here, Watsuji and Heidegger appear as a piece. The latter adds that it is through the enactment of concernful being that such betweenness is recognized as a function of what humans can care about, both as a pragmatism and as part of the symbolic meaning of the spatial self in its reflective self-understanding and its 'effectiveness' as a historical being. Not that the space of the agora completely nullifies this function. It rather attempts to use our need for meaning in an originally meaningless world against us by supplying us with one dimension of its import: that the same experiences have the same meaning for all and this makes life easier. Cultural differences, linguistic diversity, biographical idiosyncrasies, all may be overcome through the theater of agora. It is this call that tempts us to such a market each day. For the major task of the subject in modernity is to make connections with those who are as given different from oneself. This task in terms of spatiality has been outlined in the above. But it is the first aspect of the objectivity of spatiality that places itself in the way of such a goal. Anywhere, especially in its guise as the agora - originally thought of as the place where people could indeed make the intersubjective work, make the connections that in turn made the polis a viable human entity - plays upon its borrowed reputation as the place of meaning-making. Our concern for its misuse and abuse emanates from the sense that we can travel around and about it without getting anything about ourselves or coming to know the other in any meaningful way, the experience of our modern anonymity writ into the world of objects: "Spatiality, which is saturated in a factical manner with concern, has its distances - it is there as: too far, nearby, through this street, through the kitchen, a stone's throw, behind the cathedral, and the like. In this spatiality is found a familiarity with its references which prevails for a whole at a particular time and these references are always those of concern." (Heidegger, 1999:78 [1988]). All of these kinds of connotations actually reference the hereness of our being-familiar. It is because we already know how to get there from here that the thereness of where we are directed to or where we direct others to with such vernacular expressions is not truly there. Nor is it just anywhere. The destinations referred to are quite specific and are also part of our interiority. We have 'been there' and thus that there is a there no longer. Only in the most basic sense that we are not exactly there in space at the moment we remain rooted to our own place and cannot be in two places at once as objects; we can be so in our mind's eye, in phantasms and their projects, in dreams and in visions etc., in other words, as in aspects of our subjectivity - renders the other place as a 'there'. It is also 
rendered for the other as an authentic there because they might not have been there as yet. Indeed, this may be the reason why we are giving them direction in this manner. Even so, neither conception of thereness in Heidegger can be co-opted by the agora of anywhere by means of concern or concernful being. The care we take in making this other place precise and part of our experience stands against all versions of 'nothingness' that might attempt to infiltrate and occupy such a space.

It is exactly this point that the anonymous and repetitive spaces of contemporary agora avoid. Their appearance and return at every turn, peering into our horizons with a sustained and even stunning ostinato completes itself in our ability to use them without any sense that we have to care about them, or those that are within them. The sheer number of these kinds of non-places that give their air of anywhere-anytime-anyone-anything to all comers resists a classification or even a mythology. One wonders what the narrative poems, the sagas or the epics would look like if their chief content were the scripts of fast food servers and automatons. Such repetition would mock a Whitman or an Eliot. This is indeed 'the way the world ends', except that it does not quite end but repeats itself ad nauseum, which would be even worse. The separation of earth and sky, an act which can be found in all agrarian systems of myth and perhaps others, never talks place in the agora, where what meets the eye on the ground cannot be discerned from what populates the skyline. Story upon story of multi-leveled anywhere, beckoning one off the street-side and its vendors to those 'a cut above' in the higher rent district of a single tower let alone a city block, completely overshadow the earlier intensities of storied hero and villain, dark and light. The god of separation is dazzled into dumbness, before ever he can part the seas of what has seized human consciousness. Yet we need this original distance, the purpose of his act: "Only then, as a result of his light-creating and space-creating intervention, was there heaven above and earth below, back and front, left and right - on other words, only then was space organized with reference to an ego." (Neumann, 1970:108 [1949]). In Agora, the ego is no longer a self, spatial or otherwise, but an object to be appealed to, caressed or 'stroked', as the casual idiom has it, with a view to enhancing its vanity. Everything appears to be organized around me, flattering and genuflecting, but the simple observation that anyone who follows me receives exactly the same treatment immediately puts to rest any delusions I may have harbored regarding the 'care' that is being directed my way. Having anything 'my way' or even 'doing it my way', a perennially popular sentiment in song and in life, is part of the circuitous circus of shameless sham. With the realization that anywhere has no special regard for myself or anyone else - we are all the next client, shopper, patient, or even subject in the mist subjected sense of the experience - we can take the next observation we make into account: that is, when we attempt to find meaning in the space of Agora we are defeated by its surfaces. There is in fact no depth here corresponding to that of the here or the there, or yet more importantly, to our interiority. What you see really is what you get in Agora, and this is also billed as part of its easy charm. We also find ourselves prone to mistaking such charm for charisma, but the latter can never be faked. Anyone who has ever been on a first date knows how easily the former can. Politicians, for instance, but also salespersons of all kinds, attempt to blend the one with the other, with middling results. No matter, because what sales there are, what power is gained, what resources are accessed, are quite enough to keep the whole ball rolling 
along. No red death attends this masque as its masks are too ready to fool and deflect even for the most obscene intrusion.

\section{Our Subjective Response to Objective Alienation}

Fortunately, we are still enough of ourselves to make a comparison between the surfaces of Agora and the beneath and between residing within us and we assume within others. Compared with the shills and sirens of the space of anywhere, even the most naïve human being finds himself suddenly heavy with breath: "This concept of an inexhaustible inner domain is the correlative of the power of expressive self-articulation. The sense of depth in inner space is bound up with the sense that we can move into it and bring things to the fore. This we do when we articulate." (Taylor, op. cit. 360). Such expression, reasoned appeal and argument, articulatory claim and counter-claim, dialogue and dialectic, none are possible in Agora. Another simple experiment: though some retail venues are now encouraging customers to speak meaningfully to their servants, one wonders if this too is being billed as a commodity, a new and improved space of consuming where one can prove that the others really do exhibit 'care' if we also do so. This is likely true of human relations in general and hopefully also in a shared crisis - though obviously not in all cases, at least not yet - but we retain our doubts as to whether or not agoric space can contain such humanity. At some point, likely after but a few moments of paid-labor time, we must forsake the 'caring' and attentive words. By entering into such a temptation, though it appears to be humane, we are placing ourselves as well 'on the clock', and within the ambit of anywhere. Unlike our beings, reflecting without becoming introverted, the surface structures of Agora defy potential depths. One must learn to stay afloat, and while we might not exactly drown in such shallow waters, we certainly can be swept along at a disconcerting pace. It is said, tritely in most cases, that 'still waters run deeply'. Here in Agora, every current flies along and our 'liquid modernity' is most noticeable when we engage in the comparison of what we discover when we are alone and apart from its sorry sostenuto: "The inescapable feeling of depth comes from the realization that whatever we bring up, there is always more down there." (ibid.).

Although the effects of the surface - seeing what we want to see all the time and anywhere we look, which is often seeing ourselves as we present ourselves to the world, our most practiced selves in space, our most comfortable moments in time - are available to us as a pure pragmatics of daily life, we are aware that this is where they should be placed, without any nobler aspirations to which they could only fall short and thereby render dissolute. We do not find in them the whole of our concerns let alone a response to all of our cares. At best, Agora stimulates our nerve to risk more of ourselves. If we do so only on the open markets of idols or tribes we might lose all. But most of us reserve the space of interiority for places different than just anywhere. We have other interests in working out our emplacement in the world, "For besides purchasable goods unique things that are without price influence our location; those individual characteristics of places and people that cannot be interchanged, all those imponderables of production and consumption that often mean incomparably more to us than the economic process proper." (Lösch, 1967:242 [1945]). But in order to take our place amongst more than an effervescence of scenic vanities or a charlatanry of arsenic chalets we must call our focused attention to the tendentious tendons that work the magic 
before us. There is some depth, after all, even to the surfaces shining up at us with the flower of Narcissus. That which sails along even shallow water must have rigging, a wheel - though locked in a meandering and serpentine course ready to always double back on itself in the mocking mimicry of the uroboros - and a crew of human kindred to ourselves. Finding these things out and making them subject to our own experience of things in general is a good step along the new road that actually has a direction to it; that is, one that through negation and division eventually exeunts the stage of duplicity. Mythologically, such a discovery is part of the origin of consciousness in general, and the origin of specifically individual and reflective consciousness particular. But “...when we scrutinize the acts upon which consciousness and the ego are built up, we must admit that to begin with they are all negative acts. To discriminate, to distinguish, to mark off, to isolate oneself from the surrounding context these are the basic acts of consciousness." (Neumann, op. cit. 121). We are reminded quite rightly of the scientific method to this regard. The natural, or psychological, context is broken up, broken down, broken away from its constituent mélange of force and consequence, implication and reality. Once achieved, singular discriminating consciousness must ironically find some means of communicating with that it has been broken away from. It is this effort that creates culture proper, history following hard upon the dissolution of the primeval anti-history of the uroboric state. Language, record, narrative, the passage of time and the begetting of children, all are necessary to the transition from anywhere to any specific other place. The ability to identify oneself within the agora means that this opened space too has to expend effort in communicating. The agoric quality of anywhere may be based upon that uroboric, but it cannot mimic the original egg of creation simply because what was held within its universe has splintered and splattered everywhere. Nothing can put it together again, as we are analogically warned in the nursery rhyme. What wholeness there can be now lies within ourselves, and hence the individuation of the cosmic egg story in a cautionary tale for children. We are less concerned with the shards that populate the 'back of a god' then we are with bits and pieces of a life lived ever onwards and outwards. We must grasp the fact that it is we who enact reconstruction and recollection. Most unlike the model for agora, the character of anywhere serves itself to make the distinction between selves, though for its purposes simply as a numeric quantity as in amount of customers etc. "However, I know that every sign has its author, and that every author has his own thoughts and subjective experiences as he expresses himself through signs. It is therefore perfectly proper for me to ask myself what a given predecessor meant by expressing himself in such and such a way." (Schutz, 1967:209 [1932]). This idea of something coming before myself can equally apply to an historical event or figure as well as to the moment previous to the one in which I engage in interpretation and perhaps in communicative response. 'What has happened?' is a question that can only be asked after the conceptions of both happenstance and happening themselves occur. Even the former may be put aside for the time being, as the assignment of probability to events in the space of anywhere is actually part of the interpretive process. This process is itself arrested in the face of immanence. Rationalized, it often gives way to a casuistry or sophistry of the 'Das Man' figure, which perhaps may be likened to a combination of the shadow and the generalized other. Indeed, a reasonable definition of Das Man may well be the shadow of the generalized other, as our perception of the social and its representatives - 
and we also occupy a constituent part of this larger sociality for others - carries within it the shady apprehension that we may not simply do as we choose and that this 'figure' or 'event' must be taken into account with our every move. It follows us like our own individual shadow, and its source is not a temporary and transient blockage of a higher light source, but a permanent limitation on our ability to light our own way. We can only gaze in startled awe at this phenomenon, if we take it seriously at all, for its intrusive character seems to be at odds with its passive, even inert presence in the back of our individuated consciousness. But the struggle to maintain such an individuality, the distinction between the womb-state of cosmogonic fame and the current result of cultural complexity and material sophistication, should remind us that for human beings the challenge is an ever-present one. We must eye it with alertness simply because it has its eye upon us and never removes it. The tension between these interlocked gazes is not so different from any form of sudden confrontation with the world or with others, for "... what happens to you when you are knocked to the ground by some astonishment: You go very still at some point in yourself and become entirely eye." (Lilburn, in McCaslin, 2011:72). A combination of natural and cultural factors can create this incidence. Sometimes it may be put down to accident rather than to design. For the old metaphysics, nothing was accidental, and thus the experience of anywhere could not exist. The happenstance of probability - it can be calculated, sometimes with great precision, but never with the certitude that characterized the agrarian mindset, at least regarding ultimate questions if not the next harvest - lends cantor to the cant of the open space of agora. Once again, this aspect of anywhere is not an opened spatiality, indeed, it is this understanding that we must construct against the trite trivialities of agora, but ever and always a design for making our individuality 'easy' on us. Such a space consoles us by appealing to our common humanity, but in doing so it makes humanity itself common. No astonishment is possible in its sway, for the function of awe in the world is to take our breath away and not to make us breathe the easier. It is the disconcerting sight of the different and the alien that reminds us that we have a consciousness at all: "Skedans on a stormy day looked menacing. To the right of the Bay immediately behind the reef, rose a pair of uncouth cone-shaped hills, their heads bonneted in lowering clouds. The clumsy hills were heavily treed save where deep bare scars ran down their sides, as if some monster cruelty had ripped them from crown to base." (Carr, 1941:80). Before we have even set foot on the shore such a place has warned us off. The knowledge that we have destroyed a culture also provides a threat from beyond the grave. Only the dead remain in these places, but they do remain.

Such a place and its denizens could not be 'just anywhere'. Nor is it populated by 'just anyone'. We, in turn, cannot be merely any other person when confronted with it. Astonishment, perhaps, but even more so, awe. Both awful and awesome, the 'bedlam' of surf, the rapacious rocks and reefs, the glowering forest and the sheer suddenness of the mortuary poles cannot but make a deep, if inarticulate, impression upon the visitor, especially if she is from the 'outside', daring to peer into the shadowy glass. Awe itself is a value-neutral concept. It presents itself as is, as part of the world as it is. Its musts and must-nots are part of our attempt to comprehend its appearance, its apparition. We can, of course, shrug them off, given a little time and some distance in actual geographic space. We can return to the world as we had known it. But we can never quite return fully to what agora expects of the one who 
is like the other one. At length, we realize that agoric space does not contain reality at all. Carr had many experiences of this sort. Indeed, it seems that she sought them out deliberately, as the artist is inclined to do. Claudio Abbado's insightful remark about Mahler's suffering comes to mind here, where the conductor reminded us that although Mahler indeed suffered, he was also 'good at suffering'. The spatiality of this tension - the apprehension of apprehensiveness, the comprehension of the comprehensiveness of subjective experience as the enactmental complex pushed aside by agora - is for Watsuji the actual 'Climate' of our intersubjectivity. Thus, "Environmental space arises when one eliminates the tension spread over subjective spatiality and then stands on the standpoint of the individual [ ] In spite of this, the origin of space lies in the 'betweenness' of subjects, that contradicts the standpoint of the individual." (Watsuji, in McCarthy, 2014:2). When even the otherness of a subject is not immediately grasped, the result is not the recession of tension but its increase. This might grow to the point of feeling menaced. Especially so if we are encountering a place where the only others have acceded to the ultimate otherness that awaits us all. It is like visiting the Isle of the Dead before our time.

There can be no 'between' in these places because everything is at such a moral and existential distance that the specific there, its landmark or its sign, in Schutz's sense, is invisible. Even if we are suddenly rendered 'only eye', some other instrument is required for us to see, let alone observe. Unlike a wild place like Skedans, on Haida-Gwai, made all the more so by the loss of humanity suffered there, each society in its own way strives to perfect the organization of space in the midst of those who live in the present. The dead are always set apart, either above or below, away from the space of the living, even if their conviviality is part of the good society. Indeed, this conviviality may only be assured and reassured by the distance between the living and the dead, a distance which itself is preserved in the experience of the day to day as a living being. For the West, "The concept of the ideal town blossomed first in the Renaissance. Octagons and squares predominate in the sketches of this period, and a twelve-sided shape seems to have been proposed first [ ] after 1540." (Lösch, op. cit. 441). Cemeteries underneath the city, as in Paris, or at some distance horizontally, often placed in an area where no anticipated growth or development would appear salutary, also began to be planned out at this time. The idea of the necropolis was in some way an extension of the planned earthly residential neighborhoods. Of course, it was not until the widespread advent of the automobile that we begin to see a true suburbia, first in cities like Los Angeles in the 1920s. Motivations often seem ad hoc, and admittedly it may be as difficult to plan a city as it is to plan an individual life. All kinds of events anomalistic to the ideal occur, and "...such deviations must be justified by adaptation to nature or to some practical purpose, or by an assured artistic result." (ibid:444). Skedans no doubt nestled uncomfortably within the relentless nature of its region and yet still managed to satisfy both a pragmatic and an aesthetic. But since both of these outcomes are strange to us, the place proper remains a mystery, its conception beyond even the hinterlands of agora.

\subsection{Implications of the Resonance of Previous Spaces in Global Objectivity}

Like the totem poles of the ancient winter villages that dotted the North West Pacific Coast, all spaces that hold out against the routinizing forces of agora, the hollow hallmarks of 
anywhere, have within them the landmarks of structural valuation. These are often structures in the usual sense as well, in that they can be dwelt in or at least used in some way by humans. But it is their signage that is of the greatest import, and like the totems, they speak to the locals about their culture and what it means historically and traditionally. Before the modern period, the presence of the conduits to the beyond, to meta-presence, were ironically, accepted as a facticality of daily existence. Culture could not be imagined without them: "The landscape is thick-sown with shrines, temples, churches, monuments, and memorials, marking the spot where religion and art deposit their archetypal contents in our temporal space, and everywhere the transpersonal canon of values stamps itself upon the community it has gripped." (Neumann, op. cit. 374). Though the value-content of what is to be considered beyond both the individual human being but also beyond the this-world of the everyday and of mortality has shifted dramatically, the signage that modernity posts of itself still mimics the old models. Agora is also strewn - littered might be an even better term here - with landmarks that proclaim the values of market and state: banks that look like Greek temples, museums that look like churches. Though the more direct stylistic mimicry that was de rigeur in the eighteenth and nineteenth centuries has fallen by the architectural wayside, the aura of these new places of worship remain. Originally, these places attempted to borrow the status of their predecessors. The state took on the mantle of the church itself, and the banks the churches themselves. And of course we still fetishize stadia and the events held within them. But agora responds to tradition in a manner that human history had not yet seen. It is a kind of non-response, uncommitted, or at least feigning the relativity of all values while promoting a very narrow set of them. Yet we are tasked with the shape and course of our own histories. The shift from the gods of love or the mascot gods of the Near East to those of Mammon is one thing, but on top of this we live in the time of the afterlife of all gods. Why deny an afterlife to a god when most of us still preserve the idea, however quaint it may seem to the rationalist or the utilitarian, for ourselves? At once we involve ourselves in the agoric space of the transpersonal, not only by co-opting one of its key features - that consciousness continues in some way and its tenure indefinite - but by making these values more and more personal, private and acting them out away from an agora which has already rejected them. This too has its non-responsiveness, but it is not a failure to respond at all. For "...a nonresponse is always a modality determined in the space opened by an unavoidable responsibility. Is there then nothing more to say about nonresponse? On it or on the subject of it, if not in its favor?" (Derrida, 1995:17 [1993]). The personalization of metaphysical values, especially those of the former world system given birth by agrarian relations of production, may seem like a retreat. Public religion, even public art or science has become routinized and rationalized to the extent that individuals can no longer recognize their role in it. This is one major effect of agora and its contribution to the conception of anywhere. The spatiality of value becomes more personal and perhaps even idiosyncratic. We may have beliefs but they have lost their primary and primordial purpose. They do not bring people together in a community. Beliefs that are officially shared in the public shrines of the agora are overlays for other goals, as religious 'affiliation' overlays networking. One can be asked in agora about one's religious affiliation, perhaps also with regard to one's political affiliation as well, but it is more rare to hear the question 'What are your religious beliefs?'. Indeed, we might 
bridle at the way this is phrased. Similarly, and perhaps following from, the more well-known example of the difference between being asked 'What do you do (for a living)?' versus the more untamed 'Who are you?', our response is already set up to be given as a non-response. At once a kind of avoidance behavior - how would we, in fact, respond to an existential query about our very identity? - as well as a way in which the wheels of everyday intersubjectivity are greased, such non-questions - from the perspective of a metaphysics, at least - are wholly oriented to allow the interlocutor the easiest way out. Of course, one might have a low status occupation, or one may have no religious affiliation or belong to a marginal church or sect, but in general we can answer such questions without blinking. This said, it might also be fair to say that these non-questions of agoric interaction are also quite middle-class or middle-brow in their ambit. They are not designed to spark reflection or aid in self-understanding. Alone, they cannot push us to embark on a quest for any vision, however parochial. They can be exchanged without question, questions outside of questioning, floating along in the artificial spatiality of that which has come out of less tactful state. Both question and response can be centered on what we imagine to be common experience. If the spaces values do not unite us, the places of day to day living do: "In both cases the environs relate to a center - the beholder of the metropolis. Only by way of these economic relationships do geographic peculiarities influence the region that has spring out of pure space..." (Lösch, op. cit. 130). Here, the 'economic' must be taken in the sense of the most direct or easiest route. The most economical thing to ask of an unfamiliar person, a professional colleague or acquaintance, or even of a friend in certain circumstances, is an exercise in the glad-handing of agora. One can ask such a question of anyone, anytime, anywhere.

This kind of ritual genuflection, greeting, the shared understanding that 'How are you?' cannot possibly be taken seriously, its banal improvisations of opening and closing, of stilted and even jaded aphophasis - 'Have a good day' might be the end-run partner to 'How are you', for instance - suggest that what we are experiencing is the rejection of intimacy. The new transpersonal is the anti-personal. In its hey-day, the mytho-poetic universe could not have been anti-personal in any direct manner, for the individual, the personal, and the private were not part of the cultural imagination. Now that they very much are, or at the very least, we desire them to be so with a dangerous kind of desperation in the face of the global situation and the puzzles of public life, perhaps the efforts that are extended in keeping them private area the way we keep them sacred. We should not speak of sacred things in the mundane sphere of agora. These things cannot be broached just anywhere. We should act out our genuine tragedies and joys only within the more private space of intimate acquaintance and life partnership. This is the only way in which the modern human preserves her humanity. Like the tragic theatre of the classical period, we should not attempt to make its poignancy into a spectacle: "In its original form it was theater without spectators, ritual and not a representation of reality or of idealities. It aimed not at theological, political, or psychological pedagogy, but at creating an experience of transfiguration." (Lingis, 1989:74). Steeped as he was in the historical authenticity of such events, Nietzsche's own imagined 'transfiguration' that more or less ended his working life may be seen as somewhat inevitable. In this way the greatest prophet of the post-modern was not yet even modern. The square in Turin even in 
1889 was an agoric space, and not in any way sacred. Yet we cannot be too swift in an ironic rendering, because it was precisely the mundanity of the sorrow and tragedy of daily life that gripped Nietzsche and permanently disfigured him. Perhaps his antiquity, his inner temple was such that he saw all life was being played out in these tragic proportions that in fact were no larger than life. Perhaps this was also so for the transfigurational rituals of the Greeks and their neighbors. If we look at this episode in modern thought and modern intellectual biography spatially, we can apprehend its expanse across time. Nietzsche's modernity was precisely the ability to recognize that in the finitude of a now godless world, tragedy and heroism were now the lot of all of us simply as those who must lead human lives. With the loss of God and Man, there yet remained men, and the list of gods on earth, heroes of art and culture - though Nietzsche's tally and character of these was ever changing as he matured became more important for moderns than the mythological archetypes had been for the ancients. To make the mundane into the spectacular suggests ressentiment, if the event is a tragic one or some kind of sardonic unconcern, if the comedy and absurdity of the daily life of human beings is only to be mocked and belittled.

\subsection{Discussion: Between Anomie and Transfiguration}

Transfiguration is always spoken of as the creation of a new being. It may be a part of the event that allows us to contemplate Being or Truth, or it may be the shift from one form of being to another. From archaic period ritual theater to Richard Strauss' Töd und Verklartung, there is a sense that an utter change, a displacement in the fabric of spatiality, has occurred and we are forever altered. Indeed, we might know ourselves no longer. Transfiguration, above all else, has the autopological impact of lighting the space of Being: "Not only man's theology, religion, and ritual, but the legal and economic orders that later grew out of them, the formation of the state and the whole pattern of secular life, down to the notion of property and its symbolism, are derived from this act of discrimination and the setting of boundaries made possible by the coming of light." (Neumann, op. cit. 107). Institutions and other social structures, whether traditional or contemporary, play the role of emplacing Being within the space of beings. There is no actuality to the transcendental ideas given such succor by agrarian metaphysics, at least not recently. But their metaphor is juts as strong for us as it was for our ancestors. We have no evidence that it was any different for them, for indeed we rely exclusively on elite texts and records from earlier epochs, and a small sample of them at that, to inform us of what people might have been thinking about. We have very much the official story of history, just as we tend to keep writing it ourselves in our own time. That we have doubters and skeptics throughout the written record is as extraordinary as it is compelling. The lesson for us is to maintain such doubts and skepticisms in the face of Being in the world. Where beings tread, Being must be questioned. The sanctuary of the mundane, though not to be found in agora, where all is magnified and narrowed to act as if it was sacred, is all around us. It is a characteristic of everywhere, and not one of anywhere. 'Fire-inspired' or no, we who tread the sanctuary of joy or sorrow must do so as Nietzsche did, the 'animal rights' moment being a mere coincidence in a much vaster pattern of concernful being in the world as it is.

Spatially, the parochial worldview of each ancient region implodes. The cosmopolitan person 
comes to the fore. The centers of trade become the most wealthy and powerful depots of culture. Yet if all ideas traded and discussed carry the weight of this or that bias - women are chattel, slaves are by nature sub-human, the gods exist, to name a few stultifying sensibilities inhabiting and inhibiting the space of Alexandrian cosmopolitanism, for instance - even the great centers of learning are severely limited. Technical advances outpaced all others. We are very aware of this disconnect in our own culture, though we continue to imperil its very existence by shrugging it off: "The world in miniature, which had been so clear to the understanding, so easy to survey, fell in ruins. The 'province' became part of a greater whole that in its wide expanse was at first much more difficult to grasp, much more abstract. The attitude toward life did not broaden in step with this technical expansion." (Lösch, op. cit. 177). To keep time with the breadth of breathing the new air of a wider world is to make oneself a part of the spatiality of diverse beings. It is to lose oneself in the specificity of what intrudes upon our consciousness of what was here. The transitional phase of this kind of transfiguration is the construction of agora, the use of anywhere as if it was somewhere else, the use of anything as if it was something other, the extension of ourselves in anyone's direction as if they were The Other. We know something is up, the time of our lives as we had lived it, perhaps, or the tenancy or tenure of our residence in this or that place, or the extent of what we do own, as we stride up to the property line demarcating who can be a 'neighbor' in the mundane sense, but also often guarding against that same conception held within its ethics and spontaneity. The very climate is changing around us - perhaps it is more this metaphoric relationship with selfhood and the costs of its keeping up with technique and trade that charges us with the concern, as well as the fashion, for meditating meekly and glumly about environmental follies today - and the we must learn to breath differently: "Being-in-historical-climate means that ningen has to realize that the climate is a locus for understanding its ontological structure, wherein facticity and existence are complementing each other and, at the same time, is the locus where the relationship between man and man, man and beings, and man and nature, can find expression." (Liederbach, 2012:136, italics the text's). The betweenness of intersubjectivity is just the essential kind of space that agora denies. We cannot partake in it unless we as well play the 'as if' characters of a ritual theater gone public. Since space is now at a premium - global trade and production, logistics and borders, migration and urbanization - the conception of the spatial integration of being into the new world of collective and universal agora, anywhere finding its métier in the occupation of all somewheres, can itself spawn an over-determined analysis. The relations of production and exchange, including the exchange value of surplus humanity, of which there still is much, as well as the fading market value of a surplus humanism, might be explained away as being absorbed in the apparently less parochial space of an anywhere as part of its legitimating strategy. The concept of space could become its very own protégé, protesting our humanity as a hold-over of the here and there, as indeed even a bigotry: "The difficulty could be surmounted, to be sure, by pushing the significance too far, and developing the whole theory of production as a theory of transportation. Obviously every step in production could always be reduced in the last analysis to spatial movement." (Lösch, op. cit. 24). But movement of what kind? We have already seen that the dynamic of subjectivity in agora is meandering, the effect of its gaze akin to window-shopping. We never cross any meaningful 
threshold within its ambit, and all gambits are fastened to the petty contracts we accrue in transacting anonymity with our fellow humans. There is no liminality in agora because there is nowhere to go.

This absence of passage may in fact be the most important effect of ritualizing the profane. We lose the sense that we are but passing beings, and the world changes and carries on with us and without us. If "The meaning of ritual, irrespective of the useful effects which primitive man expects from it, lies precisely in strengthening the conscious system." (Neumann, op. cit. 126). We might say that for modern humans, the use of ritual is to strengthen the system of unthought that keeps fully human consciousness at bay. This kind of critique is of course old hat, its 'one-dimensionality' more or less fully explored. Even so, it is more the spatiality of the 'as-if' self that reneges on its multi-dimensional character and not so much that the space around it, the panoply of non-places in anywhere has such an astonishing force that is overpowers all subjective attempts to circumnavigate it. We must give the spatial self both more credit and less. More, on the one hand, because it is within our abilities to simply ignore the prescribed uses of public ritual - the borrowing of status through the object is perhaps still its first order variable - or to deliberately use such items or ideas in the proscribed manner. More often even than these options, people simply insert their own uses for things and ideas, and though these are never completely idiosyncratic, they are often quite creative. On the other hand, the spatial self that we know the best also must be aware that its record of consumption as a substitute for self-understanding has imperiously denied the space of life to most other contemporary human beings: "A large part of the modern struggle is a result of the disintegration of old or the formation of new combinations [of economic landscapes] and the attempt to prevent this." (Lösch, op. cit. 325). The major thrust of this reworking of spatiality has been to take the somewhere and force it into becoming an anywhere. The publicity of status has overtaken its public role, and one's marque in the masqued marquee of agora is seen as life success. With the remaking and the remarking and renaming of space by the objectificity of global forces, those who had come to know this or that place as home and as specific to their understanding have also had to become 'like the others', if they were not to be entirely erased. This process, not surprisingly, was first seen in the geographic spatiality of the source of what was to become shortly a more global phenomenon: "The resulting power vacuum had encouraged war, which did much to cover the practices - ethnic cleansing, politicide, population transfer, and genocide - that sorted European populations into more homogenous entities." (Hall, 2005:5). Local sources of authority were overstepped, groups related to one another through kinship alliance and linguistic similarities were to become citizens of the new mass states. Skedans, and hundreds of other communities, are sites of erasure. But there must also have been tens of thousands of like sites in Europe alone, especially in the eastern sectors, that were all the more calculatedly 'wiped from the face of the earth'. We still hear this ruthless rhetoric, often regarding the existence of the state of Israel, for instance, from enemies of this or that coagulation of the previous collective souls of archaic period populations. In fact, states that presume upon the old-fashioned groupings of people, including Israel and many others, are often more at risk, for more anonymous collections of massive populations might be led to fall back on a mythical reconstruction of an archetype that never was, like the idea of 'American' or for that matter, 'un-American'. At 
the same time, "For many years its territory rather than its people was the main concern of a state. The emigration of hundreds of thousands of citizens caused no concern, but the state was ready to make war over every square mile of land." (Lösch, op. cit. 342).

\section{Conclusion}

We need to discriminate here between the central authority's sense of just who or what group of people were 'good' or valuable citizens and who were not, given that mass exodus from this or that part of Europe, and more recently, from revolutionary states or those in constant civil turmoil, are quite happy to cast out all those who do not fit in with the new regime. Whatever variables may be involved, religious, ethnic, class etc., it should not be forgotten that the construction of the new 'immigrant' societies of the Western Hemisphere and the Pacific had their source in the same frictions. 'Useless' people were always easy to give up. The wealth of the parent country increased after such emigrations, at least for the elites who had fewer others to potentially be forced to share it with. Similarly with genocide, where it is always the most marginal people, those who cannot get out of the way of the juggernaut, who are murdered. The survivors, like the survivors of the Black Death in the 1350s, found themselves with a greater access to resources and fewer persons within their group to support with those resources. It has been argued that the Renaissance itself had a direct antecedent in the massive plague that flattened the European population some half-century before its first major advent. No doubt, at the subjective level, there must have been some soul-searching, as if one had been on a bus in an accident and had survived while one's neighbor had not. The question 'What is the ultimate value of human life?' easily bridges over into other questions, those of indeterminacy and fate, such as were found in the aftermath of the Lisbon earthquake. For those who have been evicted, exiled, or excommunicated in some other way from the place of origin, there might well be a sense that the source of all things, the origin of the species, has been put into question: "Something similar arises for many of them on the question of what makes human life worth living or what confers meaning on their individual lives. Most of us are still in the process of groping for answers here. This is an essentially modern predicament..." (Taylor, op. cit. 10). Forced into the anywhere of the agora, declared unto them to be the place where all can find their truest selves, where anyone, anytime, can be anything they need to be, the lonely crowds of massive modernity cavort as in Breughel painting, canvassing their opinions of political and popular culture and framing their psyche in the new myth that absorbs all myths: that we are only ourselves and contain no others; that we are the positive essence of ahistorical Man.

\section{References}

Carr, E. (1941). Klee Wyck. Toronto, Irwin Publishing.

Derrida, J. (1995). On the Name. Stanford, CA. Stanford University Press.

Heidegger, M. (1999). Ontology - The Hermeneutics of Facticity. Bloomington, IL. Indiana University Press.

Liederbach, H. P. (2012). Watsuji Tetsuro on Spatiality: Existence Within the Context of Climate and History. Kwansei University Department of Sociology Colloquia, 1(1), 123-138. Lingis, A. (1989). Deathbound Subjectivity. Bloomington, IL. Indiana University Press. 


\section{Macrothink}

Journal of Social Science Studies

ISSN 2329-9150

2015, Vol. 2, No. 2

Lösch, A. (1967). The Economics of Location. New York. Wiley Science Editions, John Wiley and Sons.

McCarthy, E. (2014). The Space of the Self: An Analysis of the Notion of Subjective Spatiality in the Philosophy of Watsuji Tetsuro. Paideia, $20^{\text {th }}$ WCP. 1-8.

McCaslin, S. (2011). Facing the Environmental Crisis with Contemplative Attention: The Ecopoetics of Don McKay, Tim Lilburn, and Russell Thornton. The University of the Fraser Valley Research Review, 3(1), 64-82.

Neumann, E. (1970). The Origins and History of Consciousness. Princeton, NJ. Bollingen; Princeton University Press.

Schutz, A. (1967). The Phenomenology of the Social World. Evanston, IL. Northwestern University Press.

Taylor, C. (1989). Sources of the Self: The Making of Modern Identity. Cambridge, MA. Harvard University Press.

\section{Copyright Disclaimer}

Copyright reserved by the author(s).

This article is an open-access article distributed under the terms and conditions of the Creative Commons Attribution license (http://creativecommons.org/licenses/by/3.0/). 